\title{
An intervention to reduce playground equipment hazards
}

\author{
Christine A Roseveare, Judith M Brown, Jillian M Barclay McIntosh, David J Chalmers
}

\begin{abstract}
Objectives-A community intervention trial was carried out to evaluate the relative effectiveness of two methods of reducing playground hazards in schools. The study hypotheses were: (1) a health promotion programme addressing barriers to implementing the New Zealand Playground Safety Standard will reduce playground hazards and (2) the intervention programme will be more successful than providing information alone.

Methods-Twenty four schools in Wellington, New Zealand were randomly allocated into two groups of 12 and their playgrounds audited for hazards. After the audit, the intervention group received a health promotion programme consisting of information about the hazards, an engineer's report, regular contact and encouragement to act on the report, and assistance in obtaining funding. The control group only received information about hazards in their playground.
\end{abstract}

Results-After 19 months, there was a significant fall in hazards in the intervention schools compared with the control schools (Mann-Whitney $U$ test, $p=0.027$ ). No intervention schools had increased hazards and eight out of 12 had reduced them by at least three. In contrast, only two of the control schools had reduced their hazards by this amount, with three others increasing their hazards in that time.

Conclusions-It is concluded that working intensively with schools to overcome barriers to upgrading playground equipment can lead to a reduction in hazards, and that this form of intensive intervention is more effective than providing information alone.

(Injury Prevention 1999;5:124-128)

Keywords: playground safety; health promotion; evaluation

Playground equipment related injury is a significant public health problem in many countries. ${ }^{1-8}$ In New Zealand, approximately 7400 children under 15 years of age present at emergency departments each year for the treatment of injuries associated with playground equipment, and over 1000 are hospitalised. ${ }^{3}$ Of the hospitalisations, 93\% result from falls and $5 \%$ from collisions. Younger school age children (5-8 years) are at particular risk, and the most common place of occurrence is the school playground. ${ }^{1}$
In many countries, safety standards have been developed as a means of reducing the risk of injury in playgrounds. ${ }^{9-12}$ Such a standard was introduced in New Zealand in $1986 .{ }^{13}$ The measures contained in these standards to reduce the risk of falls occurring include the provision of hand and guard rails, and specifications for access ways and the diameter of tubing used in the construction of climbing and agility equipment. Most also place restrictions on the height of equipment and require the provision of impact absorbing surfaces beneath and around equipment, to reduce the risk of injury in the event of a fall occurring. To reduce the risk of collisions between children and moving equipment, the standards require clear space around equipment through which children can pass without being struck.

Typically, the adoption of playground standards is voluntary and compliance is not high. A study carried out in Dunedin, New Zealand, in 1989 found that only $55 \%$ of playground equipment in schools had impact absorbing under surfaces, and $16 \%$ of equipment exceeded the maximum permissible fall height of 2.5 metres (m). ${ }^{14}$ Similarly, a survey of playgrounds in Montreal reported poor levels of compliance with many requirements of the Canadian standard. ${ }^{5}$ A study conducted in Boston playgrounds identified 1592 hazards in 47 public playgrounds, none of which had adequate surface materials. ${ }^{15}$

Suggested barriers to implementation of the New Zealand standard include: (1) the cost of purchasing the standard, (2) difficulty in interpreting the requirements due to their complexity, and (3) the cost of implementation. ${ }^{14}$ Efforts made in New Zealand to assist schools to reduce playground hazards have included the publication of checklists, seminars and practical demonstrations, and the identification of hazards for school officials. To date there have been no published evaluations of the efficacy of these strategies in New Zealand. However, a study conducted in United States child care centres concluded that identifying hazards, coupled with the distribution of educational materials, did not reduce hazards. ${ }^{16}$

In 1992, the Wellington Regional Public Health Service identified playground injuries as a priority for preventive action. ${ }^{17}$ From the literature we concluded that:

(1) The most promising way to reduce these injuries was to modify playground equipment to meet the standard.

(2) Providing information about playground hazards was likely to be ineffective on its own, and we would need to design a programme that 
Table 1 Checklist requirements

Requirements to reduce injuries from falls

1. Fall height within equipment is less than or equal to $2.5 \mathrm{~m}$

2. Surface is appropriate to the maximum safe fall height (up to $2.5 \mathrm{~m}$ loose fill or rubber matting surface, $2 \mathrm{~m}$ for solid tiles, $0.25 \mathrm{~m}$ for hard surfaces)

3. Impact absorbing surface extends out to the edge of the operating area, $2 \mathrm{~m}$ from fixed equipment and $3 \mathrm{~m}$ from moving equipment

4. Compliance with guard rail requirements

5. Compliance with fall variable requirements for access ways

6. Compliance with hand grip and seating surface heights for swings

7. Compliance with fall variable requirements for slides

8. Tubing used in construction of climbing frames has an outside diameter between $19 \mathrm{~mm}$ and $38 \mathrm{~mm}$

Requirements to reduce injuries from being struck by equipment

1. A circulation area of more than $2 \mathrm{~m}$ beyond the operating area for moving equipment and $1.5 \mathrm{~m}$ from static equipment, to be free of buildings, paths, etc

2. Compliance with clearance and seat design requirements for swings

would address motivational issues and financial barriers as well. ${ }^{18}$

As the Public Health Service is committed to evaluating the effectiveness of its programmes, the project was designed so that the two alternative methods of hazard reduction: (a) information only and (b) full health promotion programme, could be evaluated. This paper describes the project to reduce the hazards. A second paper will describe the impact of the hazard reduction on injuries.

\section{Method}

The study took place in Wellington, New Zealand. Ethical approval for the project was given by the Wellington Area Health Board Ethics Committee.

\section{SELECTION OF SCHOOLS}

Twenty four schools were selected for the project: 12 intervention and 12 control schools. The 12 schools that made up the intervention group were randomly sampled from the 60 primary schools in Wellington City, stratified for size and socioeconomic status (SES), using Epi-Info RAN..$^{19}$ A further two were sampled to allow for up to two refusals. There was only one refusal from the initial selection and the first of the two replacement schools selected agreed to take part. Twelve control schools were selected by taking the schools nearest to the intervention schools in size and SES. There was one refusal from a control school. This school was replaced with the next nearest in size and SES from remaining schools who had not been approached.

Written consent was obtained from all schools before the project began and schools were told whether they would be part of the control group (receiving information alone) or the intervention group (receiving the full health promotion programme).

BASELINE HAZARD CHECK

A baseline hazard check on the playground equipment was undertaken with both groups of schools. A 10 point checklist was developed by the Public Health Service based on the requirements of the New Zealand Standard, NZS 5828. The items selected were based on those Evans and Chalmers considered were "particularly relevant" to the prevention of injuries $^{14}$ and were reviewed by Chalmers. Eight of the checklist items were requirements designed to prevent or reduce the impact of children falling from equipment. The other two items were designed to prevent injuries from being struck by moving equipment or colliding with stationary equipment. Table 1 summarises the hazard checklist.

The equipment at each school was categorised into groups for hazard identification, by location and equipment type, for example agility equipment, adventure play area. Hazard identification was carried out by staff from the Public Health Service after training was given by the Public Health Environmental Health Protection Coordinator and an engineer with expertise in applying NZS 5828. For every requirement of the checklist that a piece of equipment failed to meet, a separate hazard was recorded. The staff were not blind to the group to which each school was assigned.

After the first hazard check, a report was submitted to each school. The report outlined whether or not the playground equipment met the requirements of NZS 5828 and the modifications required to achieve compliance. Information on suppliers of equipment and surfacing was also included. All schools were given information so that all would gain some benefit from the study.

HEALTH PROMOTION PROGRAMME

A health promotion programme was then undertaken with the 12 intervention schools. The PRECEDE framework proposed by Green et al was the basis of the programme. ${ }^{20}$ This model recommends addressing predisposing factors (knowledge, attitudes, and beliefs), enabling factors (availability of resources), and reinforcing factors (social acceptability) in any programme. The barriers identified by Evans and Chalmers (complexity and cost of the standard and the cost of alterations) fitted well into this framework. Issues of motivation and the need to have playground safety recognised as an ongoing priority in schools, were also considered when developing the programme.

The programme consisted of:

- The Public Health Service contracting an engineer to provide a "recommended action report" to address the complexity of NZS 5828. This report elaborated on the initial hazard check by providing greater detail about remedial work required to upgrade equipment to the requirements of the standard, prioritising improvements (upgrading of safety surfacing was given top priority), and providing estimated costs of remedial work.

- A copy of NZS 5828 was made available free of any charge to any schools planning to upgrade their equipment.

- A Public Health Service project worker spent nine months working with the intervention schools and encouraging them to act on the engineer's report. She also approached local service groups, businesses, licensing trusts, and agencies for funding assistance. Schools were assisted with the preparation of funding applications to the Ministry of Education and local city council funding schemes. 
Table 2 Characteristics and hazards of the intervention and control schools, and hazards identified at baseline

\begin{tabular}{llll}
\hline & Intervention & Control & Total \\
\hline Characteristics & & & \\
$\quad$ Children enrolled & 3013 & 2694 & 5707 \\
High SES & 7 & 7 & 14 \\
$\quad$ Low SES & 5 & 52 & 10 \\
Items of equipment & 40 & & 72 \\
Hazards & & 102 & 221 \\
$\quad$ Fall hazards & 119 & 34 & 70 \\
$\quad$ Collision hazards & 36 & 136 & 291 \\
$\quad$ Total hazards & 155 & & \\
\hline
\end{tabular}

- There was ongoing communication with principals and those assigned to upgrade equipment. Upgrading was monitored to ensure compliance with the standard.

- Schools were encouraged to develop playground safety policies.

\section{FOLLOW UP HAZARD IDENTIFICATION}

A follow up hazard identification was completed one year later. The same personnel undertook the second hazard check. Although some schools had started hazard reduction, many schools had not had sufficient time to complete their upgrading. A decision was made to extend the study and do a further check seven months later. After the second hazard check, information on any equipment that was new since the first check was given to schools in a similar format to the first report. A third check was completed eight months later.

\section{Results}

The characteristics of the intervention and control schools are summarised, along with the hazards identified in the baseline check in table 2. Fifty seven hazards involved failure to comply with the crucial height and surfacing requirements of NZS 5828 (42\% in the control schools and $58 \%$ in the intervention schools). This meant that an item of equipment exceeded the maximum fall height allowed by the standard and/or the surface underneath was classified as "unsafe" for the fall height of the equipment.

At baseline, a Mann-Whitney test was used to compare the difference in hazard distributions between groups. Although slightly more hazards were identified in the intervention schools than in the controls, the observed differences were not statistically significant $(\mathrm{z}=1.11, \mathrm{p}=0.27$, calculated assuming a Poisson distribution for the counts). Similarly, at the time of the first follow up (table 3), there were no significant group differences $(\mathrm{z}=1.35$, $\mathrm{p}=0.178)$. At the second follow up, however, there was a significantly greater reduction in the intervention group than in the control group $(\mathrm{z}=2.21, \mathrm{p}=0.027)$. Eight of the 12 intervention schools had decreased their hazards by at least three and none had increases. In contrast, only two of the 12 control schools decreased their hazards by at least three; and three schools had increased hazards over that time. The median reduction in hazards was a drop of between none to one hazards for control schools and three hazards for intervention schools.
Table 3 Comparison over time for the intervention and control schools

\begin{tabular}{lll}
\hline Items of equipment & Intervention & Control \\
\hline Baseline & 40 & 32 \\
$\quad$ First follow up & 39 & 31 \\
Second follow up & 41 & 32 \\
\% Change & $+2 \%$ & - \\
Hazards & & \\
Baseline & 155 & 136 \\
First follow up & 124 & 128 \\
Second follow up & 109 & 127 \\
\% Change & $-30 \%$ & $-7 \%$ \\
Height/surface hazards & & \\
Baseline & 33 & 24 \\
First follow up & 23 & 22 \\
Second follow up & 16 & $-8 \%$ \\
\% Change & $-52 \%$ & \\
\hline
\end{tabular}

The actions taken by schools to remove hazards included the installation of impact absorbing surfaces, the removal of complete items of equipment, reductions in the height of equipment, the installation or modification of hand and guard rails, the resiting of equipment to increase operating and circulation areas, and in some cases the complete replacement of a play area.

A key result was the $52 \%$ reduction in height/surface hazards achieved in the intervention schools, compared with an $8 \%$ reduction in the controls (table 3). By the second follow up, nine of the 12 intervention schools had eliminated at least one height/surface hazard compared with only three control schools. One control school had created an additional height/surface hazard. The reduction in height surface hazards was significantly greater in the intervention schools (Mann-Whitney $U$ test, $\mathrm{p}<0.02$ ).

EFFECT OF THE HEALTH PROMOTION PROGRAMME Use of the recommended action report

The outcome expected from giving intervention schools the recommended action report was that they would use it as a basis for upgrading existing equipment. This did not always occur.

- Fifty per cent made at least some direct use of the report by changing equipment as recommended or replacing non-standard equipment.

- Sixteen per cent already had plans for new equipment and requested that the report relate to these plans rather than the existing equipment. Although this had the benefit of ensuring new equipment would meet the standard, it did not directly enable changes to be made to existing equipment that was not removed from the playground.

- Sixteen per cent were already aware that their playground equipment was noncompliant and had long terms plans to change it. The report was of little use to them.

- One school temporarily removed equipment classified as unsafe, but it was in use again at the time of the third hazard check.

- One school rejected the report.

In conclusion, the report was successful in clarifying what schools needed to do to upgrade playground equipment and gave costing options. In $50 \%$ of schools it was decided instead to partially or fully replace the hazardous equipment. We did not anticipate that so 
many schools would find replacing equipment a more attractive option than upgrading existing equipment. This meant that the benefit of the report was more limited than expected.

Copy of the standard

Copies of NZS 5828 were made available on request, but only two schools requested a copy. All schools were given information about NZS 5828 requirements through the hazard check report and the engineer's report.

Funding

Progress towards upgrading in some schools was hindered by the lack of funds. It was apparent early in the project that funding from community service groups and businesses was not available. Schools that raised money for upgrading equipment used mainly conventional fund raising methods, including fairs and raffles. One school received a small donation from the local licensing trust and four others applied for recreation grants allocated by the Wellington City Council and all received small grants. Ministry of Education funding through a "dollar for dollar" financial assistance scheme was applied for by five schools in the project, but none were successful. The cost barrier was much more difficult than we imagined.

Ongoing support

This was provided to schools by the project worker who contacted each intervention school regularly over the nine month duration of the intervention (on average 14 times per school). Contact was made either by telephone, visiting, or letter.

Playground safety policies

Eighty three per cent of the intervention schools implemented playground safety policies. These policies included guidelines for inspecting equipment for hazards, maintenance programmes, the recording of injuries, and the supervision of children on equipment.

\section{Discussion}

The results show that working intensively with schools to overcome barriers to upgrading playground equipment can lead to a reduction in hazards, and that this form of intensive intervention is more effective than simply providing "one off” information.

The engineer's recommended action report was a useful tool, providing schools with a working document to assist them with planning and budgeting. It also overcame the need to purchase the playground safety standard and eased the difficulties in interpreting it. Interest was highest in those schools that were already advanced in the planning and funding stages, and the report was regarded as a bonus that would assist in the completion of their new playground. Reports were also used to persuade boards of trustees to put playground upgrading higher on their priority lists.

Despite the efforts of the project worker and schools to obtain funding, this remained a major barrier. The estimated cost of upgrading the playground equipment ranged from $\$ 2250$ to $\$ 15460$. An even greater reduction of hazards in the intervention schools may have been achieved if funding for upgrading playground equipment was more readily available.

As the health promotion programme progressed, other barriers became evident. As with many social health concerns, a number of myths surround playgrounds and injuries. The myth that children lose interest unless they have challenging and risk taking equipment to play on was heard repeatedly. The safety standards were blamed for eliminating fun and excitement from playground equipment. The attitude that "accidents will happen, you can't prevent them" is prevalent in many school communities. So, too, was the view that playgrounds were less important than intellectual pursuits, such as computers, and that injuries were part of school life. These additional barriers affected the willingness of some schools to spend funds on upgrading equipment.

A key component when working with the school communities was time, including time for the project to become established in each school and time for budgeting, planning, and consultation. This may take several years before making actual changes to playground equipment. Raising awareness about playground injuries and prevention strategies also takes time and resources. The initial 12 months allowed in the study plan for work to be completed on hazards was too short.

Our subjective assessment was that levels of motivation were a key factor. Most progress was made when schools had a motivated individual keen to focus on playground safety. Schools that made the most progress were those that had already been planning and fundraising for several years. The continuous availability of one Public Heath Service person to provide motivation and support helped these schools reach the stage of upgrading equipment or to start the planning and consultation process. The schools we worked with were randomly selected and thus had differing levels of motivation. If we had worked with schools that had already placed playground safety on their agenda, better results would have been achieved.

The study raises some important questions about the potential impact of playground safety programmes. Although it may be tempting in the current climate of limited resources to distribute information and hope it will motivate change, our results confirm the findings of previous research that this is unlikely to be effective. Achieving real change requires a longer term commitment and comprehensive programmes that go beyond information provision to address the financial barriers faced by schools.

The authors wish to thank Clare Salmond, biostatistician at the Department of Public Health, Wellington School of Medicine, University of Otago for her assistance.

1 Chalmers DJ, Langley JD. Epidemiology of playground equipment injuries resulting in hospitalisation. $\mathcal{F}$ Paediatr Child Health 1990;26:329-34. 
2 Chalmers DJ. Falls from playground equipment: an overview. Proceedings of national childhood injury prevention forum. Wellington, 23-26 September 1991. D

3 Chalmers DJ, Marshall SW, Langley JD, et al. Height and surfacing as risk factors for injury in falls from playground equipment a case control study. Inj Prev 1996;2:98-104.

4 Altmann A, Ashby K, Stathakis V. Childhood injuries from playground equipment. Hazard 1996;29:1-12.

5 Lesage D, Robitalle Y, Dorval D, et al. Does play equipment conform to the Canadian standard? Can $\mathcal{F}$ Public Health 1995;86:279-83.

6 King K, Ball D. A holistic approach to accident and injury prevention in children's playgrounds. London: London Scientific Services, 1989

7 Sosin DM, Keller P, Sacks JJ, et al. Surface-specific fall injury rates on Utah school playgrounds. Am $f$ Public Health 1993;83:733-5.

8 Mott A, Evans R, Rolfe K, et al. Patterns of injuries to children on public playgrounds. Arch Dis Child 1994;71:328 30.

9 Standards Association of Australia. Australian standard for playground equipment for parks, schools, and domestic use. (AS 1924: 1981.) Sydney: Standards Association of Australia 1981.

10 British Standards Institution. Play equipment intended for permanent installation outdoors. (BS 5696: 1986.) London: British Standards Institution, 1986.

11 Canadian Standards Association. A guideline on children's play spaces and equipment. (CAN/CSA-Z614-M90.) Rexdale (Toronto): Canadian Standards Association, 1990.
12 American Society for Testing and Materials. Standard consumer safety performance specification for playground equipment for public use. (F1487-93.) Philedelphia, PA: ASTM, 1993.

13 Standards Association of New Zealand. New Zealand standard specification for playgrounds and playground equipment. NZS 5828:1986.) Wellington: Standards Association of New Zealand, 1986 .

14 Evans MJ, Chalmers DJ. Compliance of Dunedin playground equipment with the New Zealand standard. (NZS 5828.) Dunedin: Injury Prevention Research Unit, 1992.

15 Bond MT, Peck MG. The risk of childhood injury on Boston's playground equipment and surfaces. Am $\mathcal{F}$ Public Health 1993;83:731-3.

16 Sacks JJ, Brantley MD, Holmgreen MS, et al. Evaluation of an intervention to reduce playground hazards in Atlanta child-care centres. Am f Public Health 1992;82:429-31.

17 Roseveare C. Preventing injury: a priority for public health in the Wellington Region. Lower Hutt: Public Health Service, Hutt Valley Health, 1992.

18 Roseveare C. Strategies for reducing playground injuries in schools, a literature review. Lower Hutt: Public Health Service, Hutt Valley Health, 1993.

19 Dean AG, Dean JA, Burton AH, et al. Epi-Info, version 5: a word processing, database, and statistics program for epidemiology on microcomputers. Stone Mountain, GA: USD Incorporated, 1990

20 Green LW, Kreuter MW, Deeds SG, et al. Health education planning: a diagonistic approach. Mountain View, CA: Mayfield Publishing Company, 1980.

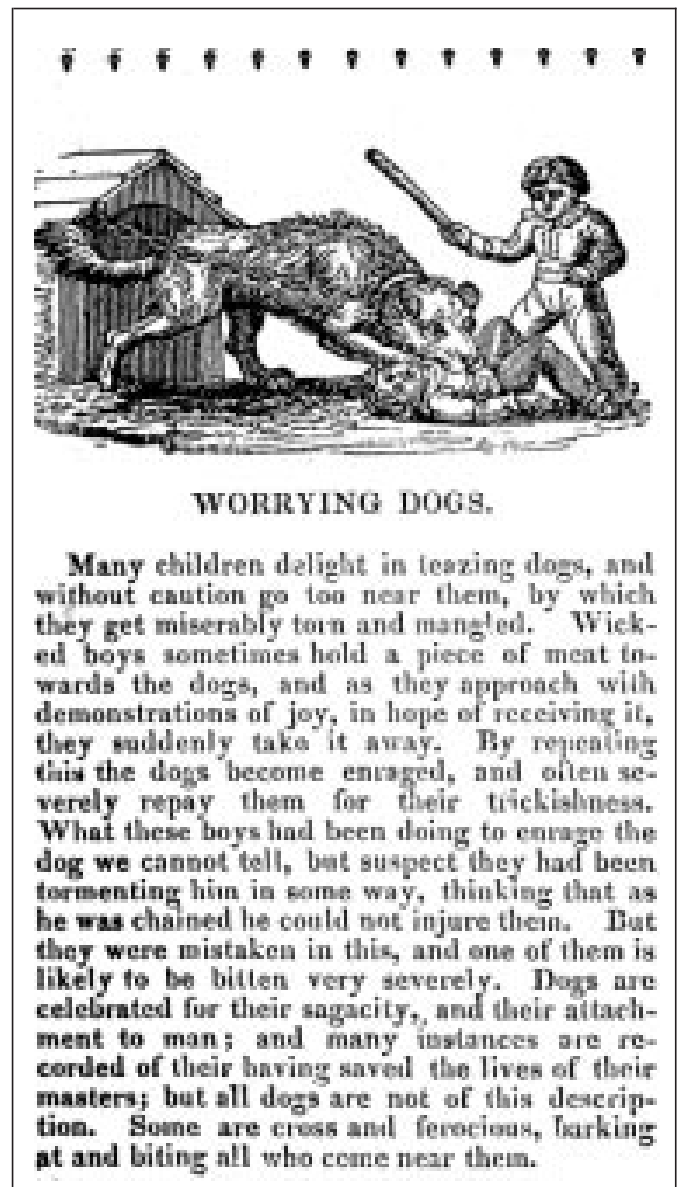

From The Book of Accidents; Designed for Young Children, New Haven, 1830. 